\title{
Food resource allocation patterns in lactating females in a long-term selection experiment for litter size in mice
}

\author{
Wendy M. Rauw ${ }^{\mathrm{a}, *}$, Pieter W. KNAP ${ }^{\mathrm{b}}$, \\ Martinus W.A. Verstegen ${ }^{c}$, Petronella Luiting ${ }^{b}$ \\ a Area de Producció Animal, Centre UdL-IRTA, Alcalde Rovira Roure, 177, \\ 25198 Lleida, Spain \\ b PIC Deutschland GmbH, P.O. Box 1630, D-24826 Schleswig, Germany \\ ${ }^{c}$ Animal Nutrition Group, Wageningen Institute of Animal Science, P.O. Box 338, \\ 6700 AH Wageningen, The Netherlands
}

(Received 14 June 2000; accepted 25 July 2001)

\begin{abstract}
Resource allocation patterns, as quantified by residual food intake (RFI), and the consequences for offspring development were investigated during lactation in 96 females of a mouse line selected for 104 generations for high litter size at birth (S-line) and in 87 females of a non-selected control line (C-line). Litters of $45 \mathrm{C}$-line dams (Cs) and 48 S-line dams (Ss) were standardised (s) at birth; other dams (ns) supported total number of pups born (Cns and Sns, respectively). RFI during lactation was significantly lower in Sns-dams than in C-line dams and Sns-dams. After weaning Sns-dams seemed to be able to restore the negative resource situation. Sns-pups were about $25 \%$ less mature than Cns-pups at all times. Maturity was similar for Cs- and Ss-pups from $2 \mathrm{~d}$ in lactation on, and about $18 \%$ and $53 \%$ higher than Cns- and Sns-pups. The pre-weaning mortality rate was significantly higher in Sns-litters (35.6 \pm 2.76$)$ than in Cns-litters $(4.95 \pm 2.23)$. The results suggest that $S$-line dams allocated considerably more resources to maintenance of offspring than C-line dams. This was insufficient to provide the offspring with an adequate amount of resources, resulting in reduced pup development and increased pre-weaning mortality rates.
\end{abstract}

mice / litter size / lactation / resource allocation / residual food intake

\section{INTRODUCTION}

Residual food intake is defined as the part of food intake that is unaccounted for by food requirements for maintenance and production, or in other words, as the difference between the food that is consumed by an animal and its consumption as predicted from a model involving its maintenance requirements, its

\footnotetext{
* Correspondence and reprints
}

E-mail: wendy.rauw@irta.es 
growth and production traits such as milk or egg production; for pigs, growth in itself is a production trait. Variation in $R F I$ can be caused by variation in partial efficiencies for maintenance and growth and by variation in metabolic food demanding processes not included in the model, such as behavioural activities, responses to pathogens and responses to stress. Since growth is virtually absent at maturity, the differences in RFI are mainly explained by differences in maintenance requirements [10]. Estimation of RFI is proposed as a tool to quantify resource allocation patterns and is suggested to be an estimate of the total amount of "buffer" resources that are available for, e.g., physical activity and the ability to cope with unexpected stresses and challenges [11,21].

Rauw et al. [22] showed that mature non-reproductive individuals (6 to $10 \mathrm{wk}$ of age) from a mouse line selected for more than 90 generations for high litter size at birth (S-line), and in particular females, have a significantly higher residual food intake $(R F I)$ than mice of a non-selected control line (C-line). This suggests that S-line females have more "buffer" resources left in the adult state than C-line females. It is interesting that particularly females of the selection line have a very high RFI, since these animals can express the trait their genotype has been selected for: a high litter size at farrowing. This higher $R F I$ in non-reproductive females may anticipate the highly increased resource demand during pregnancy and especially lactation. Indeed, an increased energy for maintenance with selection for heat loss in mice allowed for a greater litter size as a correlated effect in the study of Nielsen et al. [14]. However, since lactation is the period of peak energy demand [15] and S-line dams have to support a litter that has practically been doubled in size by selection, lactation may considerably change the resource allocation patterns. The question is whether this can be supported by an increase in food intake during these periods, or whether the $R F I$ will drop considerably when reproductive performance is included in its calculation.

In the present study we investigated food resource allocation patterns as quantified by residual food intake, and offspring development from birth to weaning in a long-term selection experiment for litter size in mice. To manipulate experimentally the energy burden of lactation, in each line, half of the females supported litters that were standardised at birth and half of the females supported all pups born. The aim was to study the food resource allocation patterns in these animals in relation with offspring development.

\section{MATERIALS AND METHODS}

Two mouse lines of the Norwegian mouse selection experiment (e.g., [32]) were used: a line selected for 104 generations for high litter size at birth (S-line) and a non-selected control line (C-line). The average total number of pups born in the 104th generation was 10 in the C-line and 21 in the S-line. 
Per line, 98 females were randomly chosen at $3 \mathrm{wk}$ of age (i.e., at weaning) and housed individually. The mice originated from litters standardised at birth, when larger than 8 pups, to 8 pups per litter. At $10 \mathrm{wk}$ of age all females were mated and stayed with the male for $2 \mathrm{wk}$. Gestation length was on the average $19 \mathrm{~d}$. Among $87 \mathrm{C}$-line females and $96 \mathrm{~S}$-line females that became pregnant, the litters of $45 \mathrm{C}$-line dams (Cs) and $48 \mathrm{~S}$-line dams (Ss) were standardised at birth, when larger than 8 pups, to 8 pups per litter; the litters of $42 \mathrm{C}$-line dams (Cns) and $48 \mathrm{~S}$-line dams (Sns) were not standardised. During the period from farrowing to weaning, all pups of 2 Cns-, 6 Cs-, 1 Sns- and 1 Ss-, and 1 Cs-line dam died.

At 13 and $15 \mathrm{~d}$ of lactation, 20 Cns-, 20 Cs-, 20 Sns- and 20 Ss-dams were subjected to an open-field test and a runway test (test duration of $60 \mathrm{~s}$ ), as described by Rauw et al. [21]. Since RFI measurements did not differ significantly between tested and non-tested animals, these animals were included in the analysis of the present study.

The mice were housed in $30 \times 12.5 \times 12.5 \mathrm{~cm}^{3}$ cages bedded with sawdust and had free access to pellet concentrate and water. The energy content of the food was $12.6 \mathrm{~kJ}$ ME per gram and contained $21 \%$ crude protein, as given by the producer. Light was left on for $24 \mathrm{~h}$ per day.

\subsection{Non-reproductive females}

\subsubsection{Body weight, food intake and residual food intake}

From 21 to $69 \mathrm{~d}$ of age, individual body weight $(\mathrm{g})$ and food intake $(\mathrm{g} / 3 \mathrm{~d})$ were measured every $3 \mathrm{~d}$. Individual body weight gain $(\mathrm{g} / 3 \mathrm{~d})$ and cumulative food intake $(\mathrm{g})$ were calculated from these data.

According to Rauw et al. [22], residual food intake ( $\mathrm{g} / 3 \mathrm{~d})$ was estimated from multiple linear regression of food intake $(\mathrm{g} / 3 \mathrm{~d})$ on metabolic body weight $\left(\mathrm{kg}^{0.75}\right)$ and body weight gain $(\mathrm{g} / 3 \mathrm{~d})$. Residual food intake is defined as the difference between the food that is consumed by an animal and its consumption as predicted from requirements for growth and maintenance per metabolic $\mathrm{kg}$ of the C-line female population [22]. Residual food intake was estimated for a "growing period", i.e., from 21 to $42 \mathrm{~d}$ of age, and an "adult period", i.e., from 42 to $69 \mathrm{~d}$ of age, from accumulated data on growth and food intake per animal over these periods [22].

\subsubsection{Asymptotic mature body weight and mature food intake}

Following Archer and Pitchford [1], modified Parks' [16] curves were fitted to individual data on body weight $(\mathrm{g})$ against cumulative food intake $(\mathrm{g})$ from 21 to $69 \mathrm{~d}$ of age, yielding, among other parameters, individual estimates of asymptotic mature (virgin) body weight ( $A$ in $\mathrm{g}$ ). A linear function by Parks ([16], p. 31) was fitted to relate individual data on cumulative food intake (g) 
to age (d), yielding individual estimates of mature (virgin) daily food intake (MFI in $\mathrm{g} / \mathrm{d}$ ). The methods for the estimation of $A$ and MFI are extensively described by Rauw et al. [22].

\subsection{Lactating females}

\subsubsection{Body weight, food intake and litter traits}

From farrowing to weaning (i.e., 3 wk in lactation), maternal body weight (g), litter weight (g), litter size and food intake (g/d) per family (i.e., dam + litter) were measured daily. From these data, for each family, pup weight (i.e., litter weight divided by litter size) (g), maternal body weight gain (g/d), pup body weight gain $(\mathrm{g} / \mathrm{d})$ and cumulative food intake $(\mathrm{g})$ were calculated. In addition, for each family, the day that the pups opened their eyes was recorded.

The pre-weaning mortality rate in families with non-standardised litters was calculated as the "total number of pups that died from birth to weaning" expressed as a percentage of the "total number of pups born". The pre-weaning mortality rate in families with standardised litters was calculated as the "total number of pups that died from birth to weaning after standardisation" expressed as a percentage of the "number of pups after standardisation".

For each individual family, the maternal body weight during lactation relative to mature virgin body weight was calculated as the maternal body weight (g) divided by the individual estimate of asymptotic mature virgin body weight ( $A$ in $\mathrm{g}$ ) multiplied by $100 \%$. Litter weight during lactation relative to mature virgin maternal body weight was calculated as litter weight $(\mathrm{g})$ divided by the individual estimate of $A(\mathrm{~g})$ of the dam multiplied by $100 \%$. The degree of maturity of the pups was calculated, according to Taylor and Murray [30], as the pup body weight ( $\mathrm{g}$ ) divided by the individual estimate of $A(\mathrm{~g})$ of the dam multiplied by $100 \%$ (the degree of maturity is calculated as the body weight divided by the mature body weight of the animal but since no data were available to estimate individual mature body weight of the offspring, the estimate of the asymptotic mature virgin body weight of the dam was used as a scaling factor instead). Food intake during lactation relative to mature virgin maternal food intake was calculated as food intake $(\mathrm{g} / \mathrm{d})$ divided by the individual estimate of the mature virgin food intake (MFI in $\mathrm{g} / \mathrm{d}$ ) multiplied by $100 \%$.

\subsubsection{Residual food intake}

The equation used to estimate $R F I(\mathrm{~g} / \mathrm{d})$ for each Cns-family was based on the following multiple linear regression of food intake $(\mathrm{g} / \mathrm{d})$ on maternal metabolic body weight $\left(\mathrm{kg}^{0.75}\right)$, maternal body weight gain $(\mathrm{g} / \mathrm{d})$, pup metabolic body 
weight (g), pup body weight gain $(\mathrm{g} / \mathrm{d})$ and litter size in control-line families with non-standardised litters (Cns):

$$
\begin{aligned}
F C_{i(\mathrm{Cns})}= & b_{0(\mathrm{Cns})}+\left(b_{1(\mathrm{Cns})} \times D B W_{i(\mathrm{Cns})}^{0.75}\right)+\left(b_{2(\mathrm{Cns})} \times D B W G_{i(\mathrm{Cns})}\right) \\
& +\left(b_{3(\mathrm{Cns})} \times P B W_{i(\mathrm{Cns})}\right)+\left(b_{4(\mathrm{Cns})} \times P B W G_{i(\mathrm{Cns})}\right) \\
& +\left(b_{5(\mathrm{Cns})} \times L S_{i(\mathrm{Cns})}\right)+e_{i(\mathrm{Cns})}
\end{aligned}
$$

where:

$F C_{i(\mathrm{Cns})}=$ food consumption of the Cns-family $i(\mathrm{~g} / \mathrm{d}) ; D B W_{i(\mathrm{Cns})}^{0.75}=$ metabolic body weight of the dam of the Cns-family $i\left(\mathrm{~kg}^{0.75}\right) ; D B W G_{i(\mathrm{Cns})}=$ body weight gain of the dam of the Cns-family $i(\mathrm{~g} / \mathrm{d}) ; P B W_{i(\mathrm{Cns})}=$ average metabolic body weight of a pup of the Cns-family $i(\mathrm{~g}) ; P B W G_{i(\mathrm{Cns})}=$ average body weight gain of a pup of the Cns-family $i(\mathrm{~g} / \mathrm{d}) ; L S_{i(\mathrm{Cns})}=$ litter size of the Cnsfamily $i ; b_{0(\mathrm{Cns})}=\mathrm{Cns}-$ line population intercept; $b_{1(\mathrm{Cns})}, b_{2(\mathrm{Cns})}, b_{3(\mathrm{Cns})}, b_{4(\mathrm{Cns})}$, $b_{5 \text { (Cns) }},=$ Cns-line population partial regression coefficients and $e_{i(\mathrm{Cns})},=$ the error term, representing $R F I$ of the Cns-family $i(\mathrm{~g} / \mathrm{d})$. The partial regression coefficients $b_{1(C n s)}$ and $b_{3(\mathrm{Cns})}$ represent the maintenance requirements per metabolic body weight of the dam and of an average pup, respectively; $b_{2 \text { (Cns) }}$ and $b_{4(\mathrm{Cns})}$ represent the requirements for growth of the dam and an average pup, respectively; $b_{5(\mathrm{Cns})}$ extrapolates food requirements per average pup to food requirements per litter. Equation (1) was fitted per day from farrowing to 3 wk in lactation.

Subsequently, $R F I$ of C-line families with standardised litters (Cs) and all S-line families (Sns and Ss) was estimated as:

$$
\begin{aligned}
R F I_{i(\mathrm{Cs}, \mathrm{Sns}, \mathrm{Ss})}= & F C_{i(\mathrm{Cs}, \mathrm{Sns}, \mathrm{Ss})}-\left\{\hat{b}_{0(\mathrm{Cns})}+\left(\hat{b}_{1(\mathrm{Cns})} \times D B W_{i(\mathrm{Cs}, \mathrm{Sns}, \mathrm{Ss})}^{0.75}\right)\right. \\
& +\left(\hat{b}_{2(\mathrm{Cns})} \times D B W G_{i(\mathrm{Cs}, \mathrm{Sns}, \mathrm{Ss})}\right)+\left(\hat{b}_{3(\mathrm{Cns})} \times P B W_{i(\mathrm{Cs}, \mathrm{Sns}, \mathrm{Ss})}\right) \\
& \left.+\left(\hat{b}_{4(\mathrm{Cns})} \times P B W G_{i(\mathrm{Cs}, \mathrm{Sns}, \mathrm{Ss})}\right)+\left(\hat{b}_{5(\mathrm{Cns})} \times L S_{i(\mathrm{Cs}, \mathrm{Sns}, \mathrm{Ss})}\right)\right\},
\end{aligned}
$$

where $R F I_{i(\mathrm{Cs}, \mathrm{Sns}, \mathrm{Ss})}=$ residual food intake of the Cs-, Sns- and Ss-family $i$ $(\mathrm{g} / \mathrm{d}) ; F C_{i(\mathrm{Cs}, \mathrm{Sns}, \mathrm{Ss})}=$ food consumption of the Cs-, Sns- and Ss-family $i(\mathrm{~g} / \mathrm{d})$; $D B W_{i(\mathrm{Cs}, \mathrm{Sns}, \mathrm{Ss})}^{0.75}=$ metabolic body weight of the dam of the Cs-, Sns- and Ssfamily $i\left(\mathrm{~kg}^{0.75}\right) ; D B W G_{i(\mathrm{Cs}, \mathrm{Sns}, \mathrm{Ss})}=$ body weight gain of the dam of the Cs-, Sns- and Ss-family $i(\mathrm{~g} / \mathrm{d}) ; P B W_{i(\mathrm{Cs}, \mathrm{Sns}, \mathrm{Ss})}=$ average metabolic body weight of a pup of the Cs-, Sns- and Ss-family $i(\mathrm{~g}) ; P B W G_{i(\mathrm{Cs}, \mathrm{Sns}, \mathrm{Ss})}=$ average body weight gain of a pup of the Cs-, Sns- and Ss-family $i(\mathrm{~g} / \mathrm{d}) ; L S_{i(\mathrm{Cs}, \mathrm{Sns}, \mathrm{Ss})}=$ litter size of the Cs-, Sns- and Ss-family $i$; $\hat{b}_{0(\mathrm{Cns})}$ to $\hat{b}_{5(\mathrm{Cns})}$ are the estimates of $b_{0(\mathrm{Cns})}$ to $b_{5 \text { (Cns) }}$ described in (1). This was done using the daily estimates of measurements from farrowing to $3 \mathrm{wk}$ in lactation. 
The respiration rate $(R E S)$ as a function of body mass $(B W)$ can usually be expressed by means of the equation $R E S=a B W^{b}$. Riisgård [23] concluded that young and fast growing stages usually show higher weight specific respiration rates $(b \sim 1)$ than older and adult stages $\left(b \sim \frac{3}{4}\right.$; [23]). In the present study, the average metabolic body weight of a pup is estimated as $P B W^{1}$, whereas the metabolic body weight of individuals of $3 \mathrm{wk}$ and older is estimated as $B W^{0.75}$.

The experimental period was subsequently divided into a period from farrowing to peak lactation (i.e., from 0 to $2 \mathrm{wk}$ in lactation; F-PL), and a period from peak lactation to weaning (i.e., from 2 to $3 \mathrm{wk}$ in lactation; PL-W). Hammond and Diamond [6] and Millican et al. [12] define peak lactation as the 15th day after parturition. Hanrahan and Eisen [7] and Jara-Almonte and White [8] observed that milk yield in mice peaked at about $13 \mathrm{~d}$ in lactation. In the present study we chose a lactation peak of arbitrarily 14 days. Equation (1) was fitted for the F-PL period and PL-W period from accumulated data on growth and food intake per family over these periods. Maternal and pup metabolic body weights of the F-PL and the PL-W periods were estimated as the average of the daily metabolic body weights over these periods.

\subsection{After weaning}

\subsubsection{Body weight, food intake and residual food intake}

For each dam, from weaning of the offspring to $25 \mathrm{~d}$ after weaning, individual body weight $(\mathrm{g})$ and food consumption $(\mathrm{g} / 5 \mathrm{~d})$ were measured every $5 \mathrm{~d}$. Individual body weight gain $(\mathrm{g} / 5 \mathrm{~d})$ and cumulative food intake $(\mathrm{g})$ were calculated from these data.

Residual food intake (g/5d) was estimated as in Section 2.1. Residual food intake was estimated for each 5-d period from weaning to $25 \mathrm{~d}$ after weaning and was subsequently expressed on a daily basis $(\mathrm{g} / \mathrm{d})$. Residual food intake was subsequently estimated for the total "after weaning period" from weaning to $25 \mathrm{~d}$ after weaning from accumulated data on growth and food intake over this period. Metabolic body weight of the female was estimated as the average of metabolic body weights for all 5-d periods from weaning to $25 \mathrm{~d}$ after weaning.

\subsection{Data analysis}

The SAS ${ }^{\circledR}$ program was used for the statistical analysis of all traits [28]. The line differences for the individual traits were tested with the model:

$$
Y_{i j}=\mu+L_{i}+e_{i j},
$$

where $\mu=$ overall mean, $L_{i}=$ effect of line $i$ (control, selection) and $e_{i j}=$ error term of animal $j$ of line $i, e_{i j} \operatorname{NID}\left(0, \sigma_{e}^{2}\right) . Y_{i j}$ denotes all the traits tested with this 
model, all as measured on animal $j$ of line $i$ : RFI in the "growing period", $R F I$ in the "adult period", $A$ and $M F I$ in non-reproductive females; number of liveborn pups, number of stillborn pups and pre-weaning mortality rate in lactating females; $R F I$ for each 5-d period from weaning to $25 \mathrm{~d}$ after weaning and $R F I$ in the "after weaning period" in dams after weaning. The pre-weaning mortality rate was tested with this model for the line effect within each standardisation level.

Differences between lines and levels of standardisation for the individual traits were tested with the model:

$$
Y_{i j k}=\mu+L_{i}+S_{j}+(L S)_{i j}+e_{i j k},
$$

where $\mu$ overall mean, $L_{i}=$ effect of line $i$ (control, selection), $S_{j}=$ effect of standardisation $j$ (non-standardised, standardised), $(L S)_{i j}=$ interaction effect of line $i$ with standardisation $j$, and $e_{i j k}=$ error term of animal $k$ of line $i$ and standardisation $j, e_{i j k} \operatorname{NID}\left(0, \sigma_{e}^{2}\right) . Y_{i j k}$ denotes all traits tested with this model, all as measured on animal $k$ of line $i$ and standardisation $j$ : daily maternal body weight, litter weight, pup weight, food intake, maternal body weight relative to $A$, litter weight relative to $A$, pup weight relative to $A$, food intake relative to $M F I$, litter size at weaning, and the day that the pups open their eyes in lactating females, and body weight and food intake for each 5-d period from weaning to $25 \mathrm{~d}$ after weaning in dams after weaning the offspring. Because of too many repetitive measurements on the same animals, the level of significance has been arbitrarily increased to 0.01 for the traits "daily maternal body weight", "litter weight", "pup weight", "food intake", "maternal body weight relative to $A$ ", "litter weight relative to $A$ ", "pup weight relative to $A$ " and "food intake relative to MFI".

\section{RESULTS}

\subsection{Non-reproductive females}

\subsubsection{Body weight, food intake and residual food intake}

Average body weight and food intake in non-reproductive males and females from 3 to $10 \mathrm{wk}$ of age in the 92nd and 95th generations of the C- and S-line have been extensively described by [22]. The present study (females only) gave similar results.

Average RFI per line in the "growing period" and the "adult period" are presented in Figure 1. $R^{2}$ values and regression coefficients of the multiple regressions per period are given in Table I. Residual food intake during the "growing period" was not significantly different between the lines; in the "adult period", S-line females had a significantly higher RFI than C-line females $(P<0.001)$. 


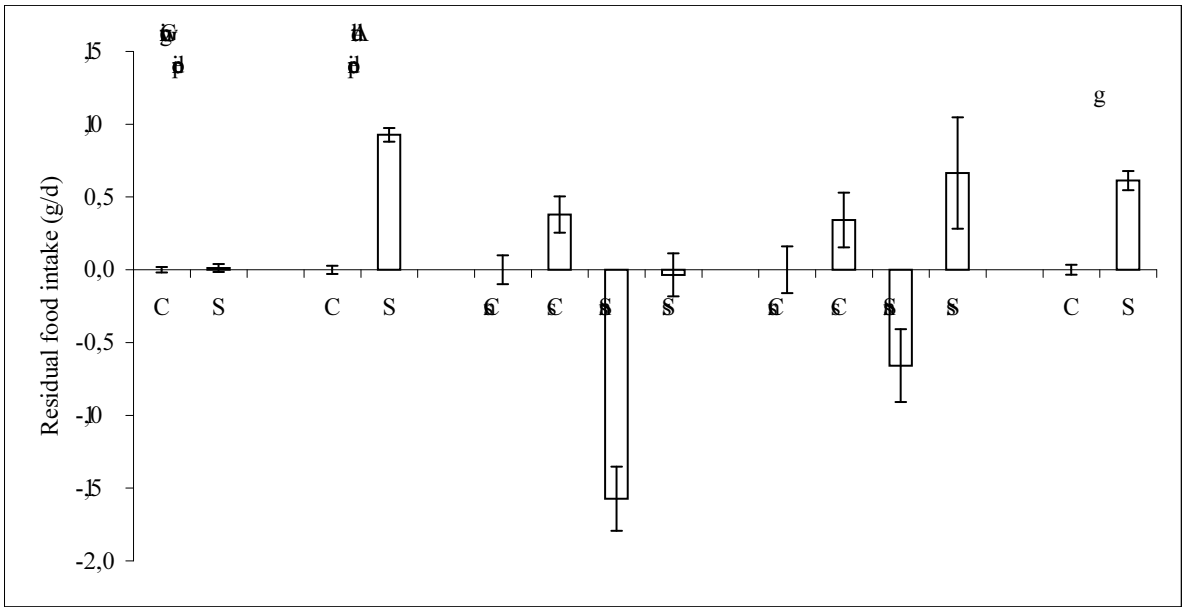

Figure 1. Average residual food intake $(\mathrm{g} / \mathrm{d})$ during the "growing period", the "adult period", from farrowing to peak lactation (F-PL), from peak lactation to weaning $(\mathrm{PL}-\mathrm{W})$ and during the "after weaning period". $\mathrm{C}=$ control line; $\mathrm{S}=$ selection line; $\mathrm{ns}=$ with non-standardised litters; $\mathrm{s}=$ with standardised litters.

Table I. Regression coefficients and coefficients of determination $\left(R^{2}\right)$ ofgunaultiphe et al. (GSE00-33) regressions for estimating RFI during the "growing period"(GP) and the "adult period" (AP), from farrowing to peak laction (F-PL) and from peak lactation to weaning (PL-W) and during the "after weaning period" (AW). 
$A$ was significantly higher in the $\mathrm{S}$-line than in the $\mathrm{C}$-line $(P<0.001)$. Estimates of mature food intake $(M F I \mathrm{in} \mathrm{g} / \mathrm{d})$ were $4.66 \pm 0.0306$ for C-line females and $6.14 \pm 0.0480$ for S-line females. $M F I$ was significantly higher in the S-line than in the $\mathrm{C}$-line $(P<0.01)$.

\subsection{Lactating females}

\subsubsection{Body weight, food intake and litter traits}

Table II presents, per line, the average number of liveborn pups and the average number of stillborn pups. Table II shows furthermore for each standardisation level in each line the average litter size at weaning, the average pre-weaning mortality rate and the average day that the pups opened their eyes.

The number of liveborn pups was about twice as high in the S-line as in the $\mathrm{C}$-line. The number of stillborn pups was significantly higher in the S-line than in the $\mathrm{C}$-line. The pre-weaning mortality rate in non-standardised litters was significantly higher in the S-line than in the C-line; in standardised litters this was significantly higher in the $\mathrm{C}$-line than in the $\mathrm{S}$-line. The $\mathrm{C}$-line pups opened their eyes earlier than the S-line pups and the pups from the standardised litters opened their eyes earlier than the pups from the non-standardised litters (Tab. II).

Figures $2 \mathrm{a}$ to $2 \mathrm{~d}$ present for each standardisation level in each line average maternal body weight (Fig. 2a), average litter weight (Fig. 2b), average pup body weight (Fig. 2c) and average food intake (Fig. 2d) from farrowing to weaning.

From farrowing to weaning, S-line dams were significantly heavier than Cline dams $(P<0.001)$. Dams with non-standardised litters were heavier than dams with standardised litters, but this was significant at 18 to $21 \mathrm{~d}$ in lactation only $(P<0.01)$ (Fig. 2a).

From birth to weaning, S-line litters were heavier than C-line litters $(P<$ $0.001)$. Non-standardised litters were heavier than standardised litters, but in the $\mathrm{C}$-line this was significant from birth to $1 \mathrm{~d}$ in lactation only $(P<0.01)$ (Fig. 2b).

At birth, the average pup weight was similar for each line and each standardisation level. From 1 to $21 \mathrm{~d}$ in lactation, the pups of the Ss-families were heavier than the pups of the Sns-, Cns- and Cs-families $(P<0.001)$. From 2 to $21 \mathrm{~d}$ in lactation, the pups of the Cs-families were heavier than the pups of the Cns-families $(P<0.01)$ and from 4 to $20 \mathrm{~d}$ in lactation, the pups of the Cs-families were heavier than the pups of the Sns-families $(P<0.01)$. The pups of Sns-families were heavier than the pups of the Cns-families at $21 \mathrm{~d}$ in lactation only $(P<0.01)$ (Fig. 2c).

Food intake was considerably increased during lactation. From farrowing to weaning, $\mathrm{S}$-line families ate more than $\mathrm{C}$-line families $(P<0.001)$. Families 


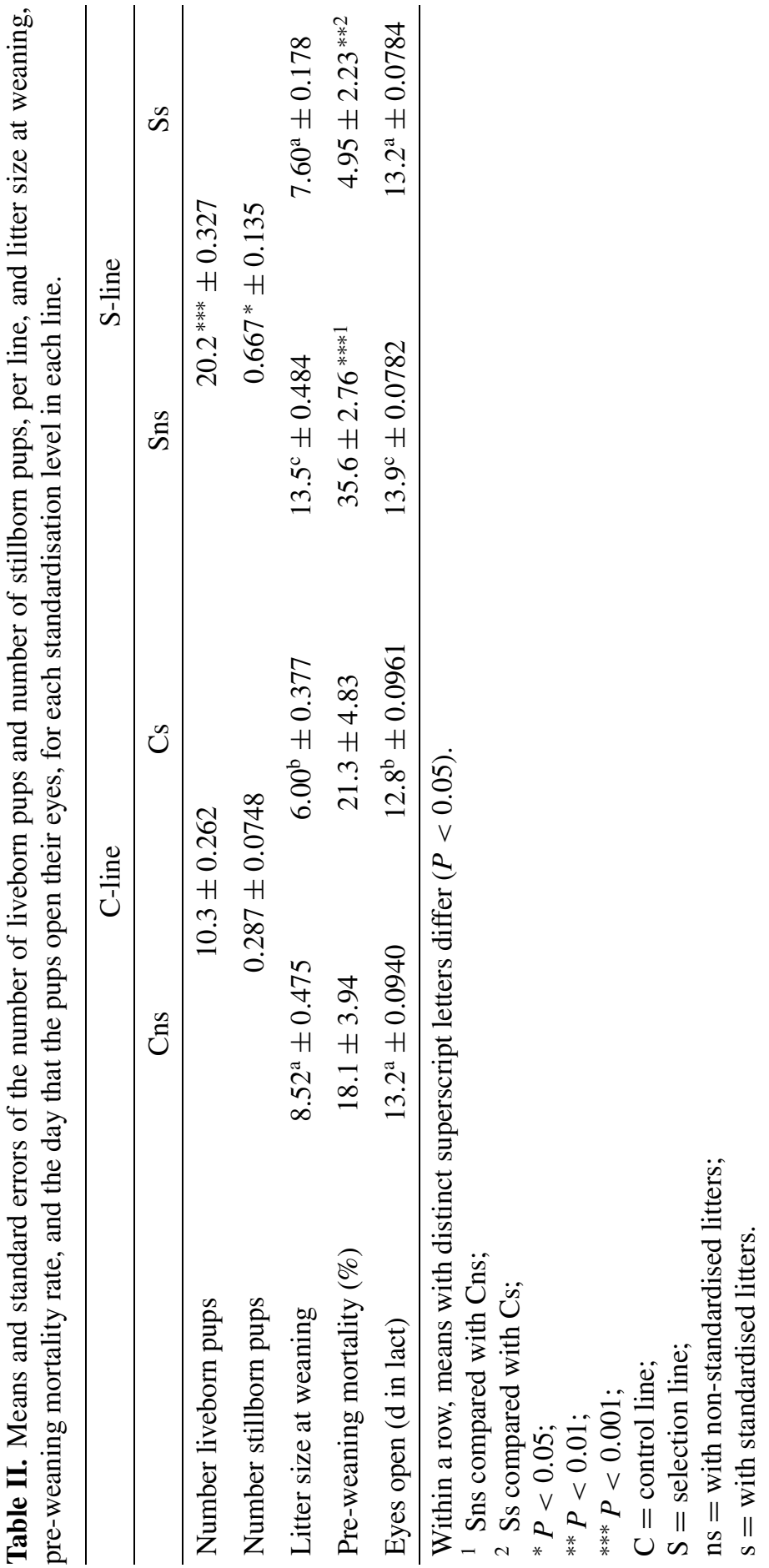




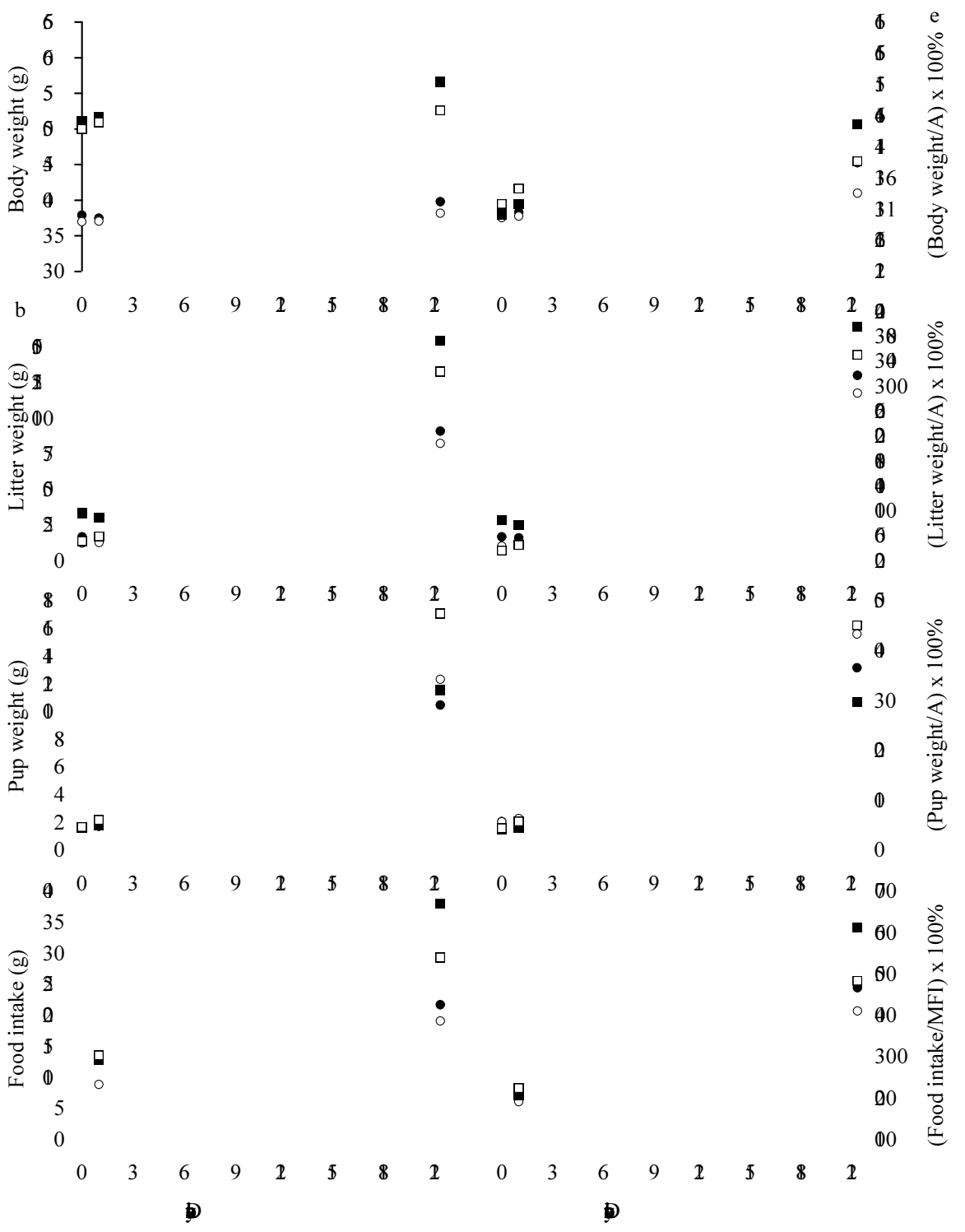

Figure 2. Average maternal body weight (3a), average litter weight (3b), average pup body weight (3c), average food intake (3d), average maternal body weight relative to $A$ (3e), average litter weight relative to $A$ (3f), average pup body weight relative to $A$ $(3 \mathrm{~g})$ and average food intake relative to $M F I$ (3h) for each standardisation level in each line from farrowing/birth to weaning. $A=$ asymptotic mature virgin body weight $(\mathrm{g})$; $M F I=$ mature virgin food intake $(\mathrm{g}) ; \mathrm{C}=$ control line; $\mathrm{S}=$ selection line; $\mathrm{ns}=$ with non-standardised litters; $\mathrm{s}=$ with standardised litters. 
with non-standardised litters ate more than families with standardised litters; in the $\mathrm{C}$-line this was significant at 19 to $20 \mathrm{~d}$ in lactation only $(P<0.01)$ and in the S-line this was significant at 3 to 10 and 19 to $21 \mathrm{~d}$ in lactation $(P<0.01)$ (Fig. 2d).

Figures $2 \mathrm{e}$ to $2 \mathrm{~h}$ present for each standardisation level in each line, from farrowing to weaning, average maternal body weight relative to asymptotic mature virgin body weight (A) (Fig. 2e), average litter weight relative to $A$ (Fig. 2f), average pup body weight relative to $A$ (Fig. 2g), and average food intake relative to mature virgin food intake (MFI; Fig. 2h).

From $7 \mathrm{~d}$ in lactation to weaning, S-line dams were significantly heavier relative to $A$ than $\mathrm{C}$-line dams $(P<0.05)$. From 20 to $21 \mathrm{~d}$ in lactation $(P<$ 0.05 ) dams with non-standardised litters were significantly heavier relative to $A$ than dams with standardised litters (Fig. 2e).

From birth to weaning, the litters of the S-line were heavier relative to $A$ than litters of the $\mathrm{C}$-line $(P<0.001)$ and non-standardised litters were heavier relative to $A$ than standardised litters $(P<0.001)$ (Fig. 2f).

From $2 \mathrm{~d}$ in lactation to weaning, pups of standardised litters had a higher degree of maturity than pups of non-standardised litters $(P<0.001)$. From farrowing to weaning, pups of the Cns-families had a higher degree of maturity than pups of the Sns-families $(P<0.001)$. From birth to $1 \mathrm{~d}$ in lactation, the degree of maturity of pups of the Cs-families was higher than the degree of maturity of pups of the Ss-families $(P<0.01)$; afterwards the degree of maturity was similar (Fig. 2g).

From farrowing to weaning, the S-line families had a higher food intake relative to $M F I$ than the $\mathrm{C}$-line families; this was significant at 1,5 , and 8 to $21 \mathrm{~d}$ in lactation $(P<0.01)$. Families with non-standardised litters generally had a higher food intake relative to $M F I$ than families with standardised litters but this was significant for $3,4,7$ to 9 , and 19 to $21 \mathrm{~d}$ in lactation only $(P<0.01)$ (Fig. 2h).

Table III presents phenotypic correlations between several litter traits. Larger litters had more stillborn pups and the pups were less mature at birth. The degree of maturity at birth was negatively correlated with the number of stillborn pups and pre-weaning mortality rate. The day that the pups opened their eyes was later in animals that were less mature at peak lactation (Tab. III).

\subsubsection{Residual food intake}

Figure 3 shows the average daily $R F I$ for each standardisation level in each line from farrowing to weaning. The $R^{2}$ values of the multiple regressions according to equation (3) per day were in the range of 58\% to $91 \%$. Since the equation used to estimate RFI was based on all Cns-families, RFI from farrowing to weaning in Cns-families was 0 . In addition, Figure 3 shows that there was not an explicit trend present for $R F I$ during lactation, as seen for 
Table III. Phenotypic correlations between number of stillborn pups and total number of pups born, and between degree of maturity and total number of pups born, number of stillborn pups, pre-weaning mortality rate and the day that the pups opened their eyes.

\begin{tabular}{|c|c|c|c|c|}
\hline & $\begin{array}{c}\text { Total number } \\
\text { pups born }\end{array}$ & $\begin{array}{c}\text { Number } \\
\text { stillborn pups }\end{array}$ & $\begin{array}{l}\text { Pre-weaning } \\
\text { mortality rate }\end{array}$ & $\begin{array}{c}\text { Eyes open } \\
\text { (d) }\end{array}$ \\
\hline Number stillborn pups & $0.36^{\mathrm{d} * * *}$ & & & \\
\hline Degree of maturity & $-0.56^{\mathrm{ad} * * *}$ & $-0.23^{\mathrm{ad} * *}$ & $-0.35^{\mathrm{acd} * * *}$ & $-0.30^{\text {be } * * *}$ \\
\hline
\end{tabular}

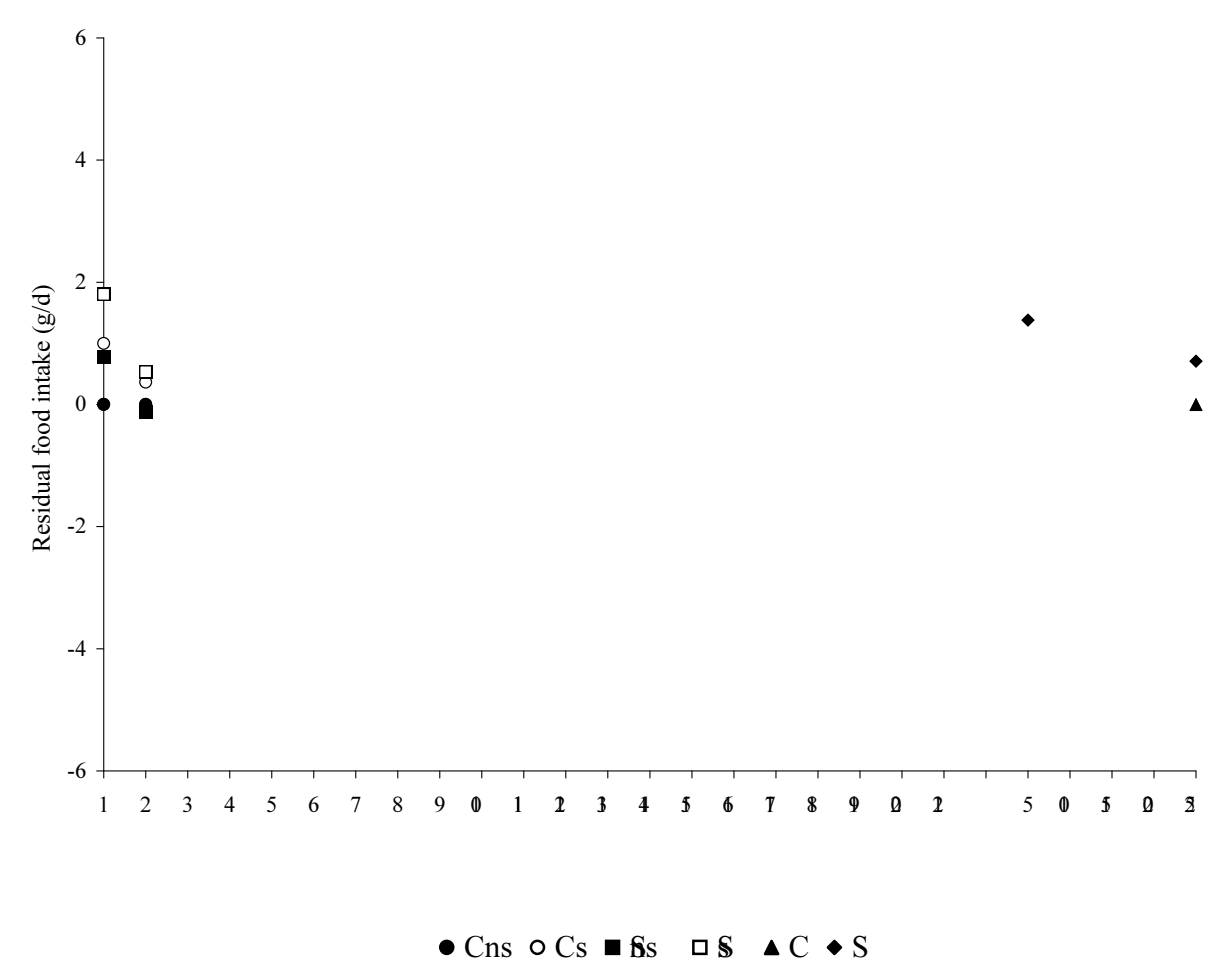

Figure 3. Average daily residual food intake (g/d) from farrowing to peak lactation (F-PL), from peak lactation to weaning (PL-W) and during the "after weaning period". $\mathrm{C}=$ control line; $\mathrm{S}=$ selection line; $\mathrm{ns}=$ with non-standardised litters; $\mathrm{s}=$ with standardised litters.

$R F I$ in non-reproductive females. Generally, $R F I$ was around and above 0 for Cs-families, both above and below 0 for Sns-families, and around and above 0 for Ss-families. 
The average RFI for each standardisation level in each line in the F-PL period and the PL-W period are presented in Figure 1. $R^{2}$ values and regression coefficients of the multiple regressions according to equation (3) per period are given in Table I. During the F-PL period, Sns-families had lower RFI than $\mathrm{C}$-line and Ss-families $(P<0.001)$. During the PL-W period, Sns-families had lower RFI than Cs- $(P<0.05)$ and Ss-families $(P<0.001)$.

\subsection{After weaning}

\subsubsection{Body weight and food intake}

From weaning to $25 \mathrm{~d}$ after weaning, within each group, body weights and food intakes were very similar for all 5-d periods. Average body weights were $37.4 \pm 0.431$ for Cns-females, $37.0 \pm 0.398$ for Cs-females, $50.4 \pm 0.521$ for Sns-females and $48.7 \pm 0.400$ for Ss-females. S-line females were significantly heavier than $\mathrm{C}$-line females. Sns-females were heavier than Ss-females $(P<$ $0.01)$.

Average food intakes ( \pm standard error) were $29.0 \pm 0.361$ for Cns-females, $28.4 \pm 0.289$ for Cs-females, $38.9 \pm 0.427$ for Sns-females and $37.5 \pm 0.624$ for Ss-females. S-line females had a significantly higher food intake than C-line females. Sns-females had higher food intake than Ss-females $(P<0.05)$.

After weaning there was a decreasing trend in food intake, but not in body weight.

\subsubsection{Residual food intake}

Figure 2 shows for each line the average RFI for each 5-d period from weaning to $25 \mathrm{~d}$ after weaning $(\mathrm{g} / \mathrm{d}) . R^{2}$ values of the multiple regressions per day were in the range of $25 \%$ to $61 \%$. Residual food intake was higher in $\mathrm{S}$-line females than in $\mathrm{C}$-line females $(P<0.01)$. Since the equation used to estimate $R F I$ was based on all C-line females, the average RFI in the C-line female population was 0 .

Average RFI per line for the "after weaning period" is presented in Figure 1. The $R^{2}$ value and regression coefficients for the "after weaning period" are given in Table I. Residual food intake during the "after weaning period" was significantly higher in $\mathrm{S}$-line females than in $\mathrm{C}$-line females $(P<0.001)$.

\subsection{Correlation between residual food intake measurements in different periods}

Table IV presents phenotypic correlations between $R F I$ in the "growing period", the "adult period", the F-PL period, the PL-W period and the "after weaning period". Residual food intake in the "growing period" was highly correlated with RFI in the "adult period". Residual food intake from farrowing 
Table IV. Phenotypic correlations between residual food intake in the "growing period", the "adult period", the period from farrowing to peak lactation (F-PL), the period from peak lactation to weaning (PL-W) and the "after weaning period".

\begin{tabular}{lcccc}
\hline & Growing period $^{\mathrm{a}}$ & Adult period $^{\mathrm{a}}$ & F-PL $^{\mathrm{b}}$ & PL-W $^{\mathrm{b}}$ \\
\hline Adult period $^{\mathrm{a}}$ & $0.63^{* * *}$ & & & \\
F-PL $^{\mathrm{b}}$ & 0.09 & 0.12 & & \\
PL-W $^{\mathrm{b}}$ & 0.13 & 0.10 & $0.51^{* * *}$ & \\
After weaning $^{\mathrm{a}}$ & $0.38^{* * *}$ & $0.58^{* * *}$ & $0.32^{* * *}$ & $0.22^{* *}$ \\
\hline
\end{tabular}

${ }^{* *} P<0.01{ }^{* * *} P<0.001$. ${ }^{\mathrm{a}}$ adjusted for line; ${ }^{\mathrm{b}}$ adjusted for line and standardisation.

to peak lactation was highly correlated with $R F I$ from peak lactation to weaning. Residual food intake in the non-reproductive period (i.e., the growing and the adult period) was not correlated with $R F I$ during lactation (i.e., the F-PL and the PL-W period). Residual food intake after weaning was correlated both with $R F I$ in the non-reproductive period and with RFI during lactation (Tab. IV).

\section{DISCUSSION}

Estimates of $R F I$ during growth and at maturity support earlier observations presented by Rauw et al. [22]: $R F I$ in adult non-reproductive S-line females is significantly higher than $R F I$ in C-line females. These buffer resources may be intended for the highly increased resource demanding processes of pregnancy and lactation.

Energy intake increases greatly during lactation to acquire sufficient energy for maternal maintenance and milk production. Food intake in mice has been shown to rise to 3.4 [6] and 4 [12] times the virgin value by peak lactation. In the present study, dams of both lines reached an intake level of around 4 times their virgin mature food intake $(M F I)$. Although Sns-dams supported at peak lactation litters which were about $58 \%$ larger and, relative to $A, 13 \%$ heavier than Cns-litters, food intake relative to MFI was only $10 \%$ higher than in Cnsdams. Around peak lactation, the pups open their eyes, and the further increase in food intake can be attributed to both the dam and the offspring. Food intake relative to MFI decreased after weaning and the difference between the Snsand Cns-dams disappeared.

Food intake varied significantly with litter size in the study of Hammond and Diamond [6]: Intake of dams with 14 pups (achieved by cross-fostering) was $25 \%$ higher than that of dams with five pups (natural size or achieved by culling). The mean rate of food intake was slightly but significantly higher in cotton rats with 6-pup litters (natural size) compared with dams with 3-pup 
litters (achieved by culling) in the study of Rogowitz and McClure [25]. In the present study, Cns-dams and Cs-dams had similar food intakes up to peak lactation, while Sns-dams ate significantly more than Ss-dams during half of this period. Since the difference in litter size between standardised and nonstandardised litters was about four times larger in the S-line than in the C-line, this may have been due to the larger effect of standardisation on litter size in the S-line. After weaning, Sns-dams still ate more than Ss-dams.

At peak lactation, extensive losses of body fat and protein reserves may occur [26]. Also lactating sows and dairy cows lose body weight during the lactation period, even under ad libitum feeding conditions $[13,29]$. In the study of Hammond and Diamond [6], body mass in lactating mice increased by $40 \%$ from the virgin state through peak lactation and then did not change after weaning. Body weights in lactating females of the present study increased up to peak lactation and subsequently decreased up to weaning. From peak lactation on, the pups start to eat solid food in addition to milk, which will progressively replace the contribution of milk to offspring growth. In spite of the larger litter size and higher relative litter mass, average body weight of Sns-dams increased to a similar level at peak lactation compared to Cns-dams, i.e., over $150 \%$ of their asymptotic mature estimates $(A)$; values decreased from peak lactation to weaning to $138 \%$ in Cns-dams and $145 \%$ in Sns-dams. Within the first $5 \mathrm{~d}$ after weaning, body weights relative to $A$ decreased further to about $127 \%$ in both lines and thereafter did not change.

Body mass and the rate of body weight loss did not vary with litter size in the study of Rogowitz and McClure [25]. In the present study, body weight increased significantly more in dams with non-standardised litters than in dams with standardised litters. After weaning, Sns-dams were still heavier than Ss-dams, but Cns- and Cs-dams had similar body weights.

Since benefits to offspring have an associated maternal cost, trade-offs and conflicts may occur during lactation when a limit to food assimilation and sustained metabolic rate can be assumed to exist $[24,33]$. If the dam allocates too much of her resources to her offspring, she may lose weight excessively, increase her risk of mortality and compromise future reproductive potential; an insufficient rate of energy export to young may decrease postnatal growth or cause offspring mortality [24]. The observed negative relationship between litter size and pup weight and increase in pre-weaning mortality rates with larger litters $([6,25]$ and the present study) indicates that a dam is to some extent able to protect her own stores at the expense of the growing young. A higher investment of resources in lactation and the processes that support this will result in a lower $R F I$ as defined in this study.

Whereas daily $R F I$ in the non-reproductive period follows a clear trend [22], the course of $R F I$ during lactation was rather capricious. A likely explanation may be that it took considerably more time to weigh all dams and litters during 
lactation than to weigh the females in the non-reproductive state; the whole process took many hours. The dams and litters were weighed in the same systematic order, but the older the pups became, the more time it took to weigh them all (they behaved like popcorn when the cage was opened); the daily scheme was therefore quite irregular. Hammond and Diamond [6] showed that food intake in lactating mice close to peak lactation rose in the afternoon, declined after midnight and was minimal at midday. Also, feeding times of the offspring may differ. When litter size exceeds the number of teats (about 9 in the $\mathrm{C}$-line and 10 in the S-line), dams have been shown to solve this discrepancy by dividing the pups into two piles and nursing the piles alternately ([6] and the present study, data not presented). Therefore, during lactation, RFI estimated from accumulated data may be a better representation of the resource situation.

From farrowing to peak lactation, $R F I$ can be attributed to the dam only, while from peak lactation to weaning, $R F I$ can be attributed to both the dam and the pups. Residual food intake from farrowing to peak lactation and from peak lactation to weaning was lower in Sns-families than in Cns-families. This suggests that S-line dams supporting litters of the size attained by selection allocate more resources to the processes that support milk production and have consequently fewer resources left to respond to other demands. After weaning, $R F I$ is significantly higher in S-line females than in C-line females, suggesting that, after weaning, the dams are able to restore the negative resource situation.

From birth to peak lactation and from peak lactation to weaning, $R F I$ was lower in dams with non-standardised litters than in dams with standardised litters, though this was significant only in the S-line. Although litters of Ssline dams were standardised to relatively smaller litters than litters of Cs-line dams, $R F I$ was not significantly different between Ss- and Cs-dams, as might have been expected; from peak lactation to weaning, $R F I$ in Ss-families was higher than RFI in Cs-families, but this was not significant. After weaning, no differences were found between dams with formerly standardised and nonstandardised litters, nor when the equation used to estimate RFI for the "after weaning period" was based on the Cns-population (results not presented).

Archer et al. [2] found a moderate genetic correlation between post-weaning and mature RFI in non-reproductive mice and suggested that animals possess an "intrinsic efficiency" that operates across different degrees of maturity and physiological states: the positive correlation results from basic physiological processes that are common to both the growing animal and the mature animal, such as the absorption of nutrients. Lactation activates processes that are specific to the physiological state and the (genetic) variation in these processes is unlikely to influence the efficiency of a non-reproductive animal [2]. The results of the present study show that the phenotypic correlations between RFI in the non-reproductive period (i.e., the growing and the adult period) and RFI during lactation (i.e., the F-PL and the PL-W period) are very close to 
zero. This suggests that, during lactation, the variation in milk production and the processes that support this dilute the importance of the processes that are common to non-reproductive and lactating animals as a source of variation in $R F I$. Indeed, the maternal body has to adapt greatly to the process of lactation. Apart from an increase in mammary size, lactating mice and rats experience an increase in liver, heart, lung and gut size to accommodate the large increase in food demands $[6,12,17,27,35]$. In dairy cows it was observed that cattle with higher milk production had higher maintenance requirements independent of body mass; a large proportion of this variation was explained by critical organ mass, especially the liver [5]. Phenotypic correlations between RFI after weaning and $R F I$ in the non-reproductive period are positive and highly significant, suggesting that common processes are again an important source of variation in RFI. Also phenotypic correlations between RFI after weaning and $R F I$ during lactation are positive and highly significant, indicating that processes that operate during lactation are still influencing the resource balance after weaning. This is plausible, since given the aforementioned adaptations of the body to the process of lactation, it will take time to return to the nonreproductive state.

Since tissues with high protein or high lipid levels have different maintenance requirements, line and standardisation differences in body composition may a explain part of the variation in RFI [20]. Protein turnover requires a high amount of resources while body lipid is relatively metabolically inactive. Therefore, animals with relatively high lipid content will have lower RFI than animals with relatively high protein content. Differences in body composition may influence $R F I$ during lactation when, e.g., the extent to which body reserves are mobilised is different between the lines and standardisation levels, and furthermore largely independent of the traits which are included as covariates in the equation that estimates RFI. Furthermore, milk composition differs between different stages of lactation [9] and may depend on litter size [25]. Since Sns-dams have to support a genetically highly increased litter size, these animals may mobilise more body reserves and their milk may be of a different composition than milk produced by Cns-dams, and the same may be true for different levels of standardisation. However, the degree of body tissue mobilisation may be positively correlated with litter size, which is included as a covariate in the equation. Forthcoming research will investigate body composition in lactating females of the C-and S-lines.

Rogowitz [24] observed that individual pups in large litters of field-caught cotton rats (6 pups) grew at $71.2 \%$ the rate of pups in small litters ( 3 pups). In the present study, pup development in Sns-pups was about 25\% lower than in Cns-pups at all times. Interestingly, the degree of maturity of Cs-pups and Sspups was similar from $2 \mathrm{~d}$ in lactation on, which may indicate that the maximum relative growth rate is similar in both lines and about $18 \%$ and $53 \%$ higher than 
Cns- and Sns-pups, respectively. This is supported by the observation that both food intake and maternal body weight up to peak lactation are lower in dams with standardised litters than in dams with non-standardised litters: a further increase is physically possible, but not used. Degree of maturity is related to the day that the pups open their eyes, which is later in relatively smaller pups.

In the study of Rogowitz [24] small litters were obtained by culling while large litters were of natural size. In the present study as well, small litters in the C-line were usually obtained by culling. This also implies that pups born in litters of a "natural size" (i.e., non-standardised and non-selected) were under the influence of "maternal effects", i.e., limited by the maternal energy export in milk [4]. A good example of such effects can be found in pigs: piglet growth rates during lactation remain, at best, half of which can be achieved under artificial rearing [18,34]. Although litter size in pigs has been increased by selection, this effect seems to result mainly from the relatively high fat content and low protein content in sow milk. Piglets are born with a relatively low body lipid content and under natural conditions, priority is given to restore their condition over improving their growth rate [18]. From birth to 2 wk of age, protein content of piglets increased from $12 \%$ to $15 \%$, while fat content increased from $1.3 \%$ to $13 \%$ [13]. Litter size may increase to the level where dams can provide energy to offspring that allows for "sufficient" offspring development. The present study shows that litter size in the S-line has been increased beyond this point: although S-line females with non-standardised litters allocate a particularly high amount of resources towards the processes of lactation, this was insufficient to provide offspring with an adequate amount of resources, resulting in reduced pup development and increased pre-weaning mortality rates.

To ensure that lactation proceeds successfully there are co-ordinated adaptations in the metabolism (homeorhesis) that reallocate available nutrients towards the mammary gland away from tissues that are not essential to lactation [3]. It is generally observed that during lactation, self-maintenance of the dam takes precedence over the maintenance of individual offspring, resulting in the death of offspring under stressful conditions whereas the dam usually survives and subsequently reproduces [24]. However, single trait selection for high litter size may result in the situation where dams "disproportionally" allocate many resources to this trait that is selected for, leaving less resources to respond to other demands. In that situation, it is most likely that resources will be reallocated firstly from traits that are not defined in the breeding goal, because they are given no importance [19].

The results of the present study suggest that dams selected for high litter size indeed allocated considerably more resources to the maintenance of offspring than non-selected dams. However, Sns-dams seemed to be able to restore the negative resource situation after weaning. Because of increased food 
demands to support genetically increased litter sizes and reduced appetites and lower body fat reserves at parturition due to genetically increased leanness, the negative resource situation during lactation is generally more severe in commercial sows, than in the mice of the present study. When a higher proportion of resources is allocated to lactation, less resources are left to respond adequately to other demands, putting the animal more at risk to behavioural, physiological and immunological problems $[3,19]$. Indeed, commercial sows have frequent reproduction problems associated with excessive mobilisation of body reserves, such as prolonged weaning to oestrus intervals [31]. Future research may investigate whether lactating S-line females are indeed more susceptible to stress and diseases and how the negative energy and nutrient balance during lactation will affect lifetime reproduction potential. Mouse models, such as those described in the present experiment, can be used to anticipate and prevent undesirable side effects of selection in the long term.

\section{ACKNOWLEDGEMENTS}

This study was supported by a grant from the Norwegian Research Council, project number 114258/111. Kari Kjus is gratefully acknowledged for carrying out the Norwegian mouse selection experiment and her help in providing and maintaining the mice of this project. We thank January Weiner, Hans Ulrik Riisgård and Christofer Knight for sending us their papers on request. This manuscript was written at the Instituto Nacional de Investigación y Tecnología Agraria y Alimentaria (INIA) in Madrid, Spain, which is thanked for providing the resources.

\section{REFERENCES}

[1] Archer J.A., Pitchford W.S., Phenotypic variation in residual food intake of mice at different ages and its relationship with efficiency of growth, maintenance and body composition, Anim. Sci. 63 (1996) 149-157.

[2] Archer J.A., Pitchford W.S., Hughes T.E., Parnell P.F., Genetic and phenotypic relationships between food intake, growth, efficiency and body composition of mice post weaning and at maturity, Anim. Sci. 67 (1998) 171-182.

[3] Bauman D.E., Currie W.B., Partitioning of nutrients during pregnancy and lactation: a review of mechanisms involving homeostasis and homeorhesis, J. Dairy Sci. 63 (1980) 1514-1529.

[4] Falconer D.S., Mackay T.F.C., Introduction to quantitative genetics, 4th edn., Longman Group Ltd, Essex, 1996.

[5] Ferrell C.L., Jenkins T.G., Cow type and the nutritional environment: nutritional aspects, J. Anim. Sci. 61 (1985) 725.

[6] Hammond K.A., Diamond J.D., An experimental test for a ceiling on sustained metabolic rate in lactating mice, Phys. Zool. 65 (1992) 952-977. 
[7] Hanrahan J.P., Eisen E.J., A lactation curve for mice, Lab. Anim. Care 20 (1970) 101-104.

[8] Jara-Almonte M., White J.M., Milk production in laboratory mice, J. Dairy Sci. 55 (1972) 1502-1505.

[9] Knight C.H., Maltz E., Docherty A.H., Milk yield and composition in mice: effects of litter size and lactation number, Comp. Biochem. Physiol. 84A (1986) 127-133.

[10] Luiting P., Genetic variation of energy partitioning in laying hens: causes of variation in residual feed consumption, World's Poultry Sci. J. 46 (1990) 133152.

[11] Luiting P., Vangen O., Rauw W.M., Knap P.W., Beilharz R.G., Physiological consequences of selection for growth. 48th Annual Meeting of the EAAP, Vienna, 1997.

[12] Millican P.E., Vernon R.G., Pain V.M., Protein metabolism in the mouse during pregnancy and lactation, Biochem. J. 248 (1987) 251-257.

[13] Mullan B.P., Close W.H., Cole D.J.A., Predicting nutrient responses of the lactating sow, in: Cole D.J.A., Haresign W., Garnsworthy P.C., (Eds.), Recent developments in pig nutrition 2, Nottingham University Press, 1993, pp. 323-346.

[14] Nielsen M.K., Freking B.A., Jones L.D., Nelson S.M., Vorderstrasse T.L., Hussey B.A., Divergent selection for heat loss in mice: II. Correlated responses in food intake, body mass, body composition, and number born through fifteen generations, J. Anim. Sci. 75 (1997) 1469-1476.

[15] Oftedal O., 1984, Milk composition, milk yield and energy output at peak lactation: a comparative review, in: Peaker M., Vernon R.G., Knight C.H., (Eds.), Physiological strategies in lactation, Symp. Zool. Soc. Lond. 51 (1984) 33-85.

[16] Parks J.R., A theory of feeding and growth of animals, Springer-Verlag, Berlin, 1982.

[17] Pine A.P., Jessop N.S., Oldham J.D., Maternal protein reserves and their influence on lactational performance in rats, Br. J. Nutr. 71 (1994) 13-27.

[18] Pluske J.R., Dong G.Z., Factors influencing the utilisation of colostrum and milk, in: Verstegen M.W.A., Moughan P.J., Schrama J.W., (Eds.), The lactating sow, Wageningen Pers, 1998, pp. 45-70.

[19] Rauw W.M., Kanis E., Noordhuizen-Stassen E.N., Grommers F.J., Undesirable side-effects of selection for high production efficiency in farm animals: a review, Livest. Prod. Sci. 56 (1998) 15-33.

[20] Rauw W.M., Knap P.W., Verstegen M.W.A., Luiting P., Body composition in non-reproductive adult males and females in a long-term selection experiment for litter size in mice, J. Anim. Breed. Genet., in press.

[21] Rauw W.M., Luiting P., Bakken M., Schuurman T., de Veer C.J.M., Vangen O., Behavioural differences in non-reproductive adult females in a long-term selection experiment for litter size in mice, Appl. Anim. Beh. Sci. 66 (2000) 249-262.

[22] Rauw W.M., Luiting P., Verstegen M.W.A., Vangen O., Knap P.W., Differences in food resource allocation in a long-term selection experiment for litter size in mice, 2. Developmental trends in body weight against food intake, Anim. Sci. 71 (2000) 39-47. 
[23] Riisgård H.U., No foundation of a "3/4 power scaling law" for respiration in biology, Ecol. Lett. 1 (1998) 71-73.

[24] Rogowitz G.L., Trade-offs in energy allocation during lactation, Amer. Zool. 36 (1996) 197-204.

[25] Rogowitz G.L., McClure P.A., Energy export and offspring growth during lactation in Cotton Rats (Sigmodon hispidus), Funct. Ecol. 9 (1995) 143-150.

[26] Sainz R.D., Calvert C.C., Baldwin R.L., Relationships among dietary protein, food intake and changes in body and tissue composition of lactating rats, J. Nutr. 116 (1986) 1529-1539.

[27] Speakman J.R., McQueenie J., Limits to sustained metabolic rate: the link between food intake, basal metabolic rate, and morphology in reproducing mice, Mus Musculus, Phys. Zool. 69 (1996) 746-769.

[28] Statistical Analysis Systems Institute, SAS ${ }^{\circledR}$ user's guide: statistics, version 5, Statistical Analysis Systems Institute Inc., Cary, NC, 1985.

[29] Tamminga S., Luteijn P.A., Meijer R.G.M., Changes in composition and energy content of liveweight loss in dairy cows with time after parturition, Livest. Prod. Sci. 52 (1997) 31-38.

[30] Taylor St C.S., Murray J.I., Genetic aspects of mammalian growth and survival in relation to body size, Academic Press, London, 1987.

[31] Ten Napel J., Genetic aspects of intervals from weaning to estrus in swine. Ph.D. Thesis Wageningen Agricultural University, Wageningen, 1996.

[32] Vangen O., Results from 40 generations of divergent selection for litter size in mice, Livest. Prod. Sci. 37 (1993) 197-211.

[33] Weiner J., Physiological limits to sustainable energy budgets in birds and mammals: ecological implications, Tree 7 (1992) 384-388.

[34] Whittemore C.T., Elements of pig science, Longman Group, Essex, 1980.

[35] Williamson D.H., Integration of metabolism in tissues of the lactating rat, FEBS Lett. 117 (1980) 93-105.

To access this journal online: www.edpsciences.org 